\title{
Formation of unsaturated hydrocarbons and hydrogen: surface chemistry of methyltrioxorhenium(VII) in ALD of mixed-metal oxide structures comprising $\operatorname{Re}(\mathrm{III})$ units
}

Maximilian Gebhard, ${ }^{\dagger}$ Steven Letourneau, ${ }^{\dagger}$ David J. Mandia, ${ }^{\dagger}$ Devika Choudhury, ${ }^{\dagger}$ Angel Yanguas-Gil, ${ }^{\dagger}$ Anil Mane, ${ }^{\dagger}$ Alfred P. Sattelberger, ${ }^{\ddagger}$ Jeffrey W. Elam ${ }^{\dagger *}$

†Argonne National Laboratory, Applied Materials Division, Argonne, Illinois 60439, USA

‡Argonne National Laboratory, Chemical Sciences and Engineering Division, Argonne, Illinois 60439, USA ALD, mixed metal oxides, Rhenium, in situ analysis, MCPs, TCR

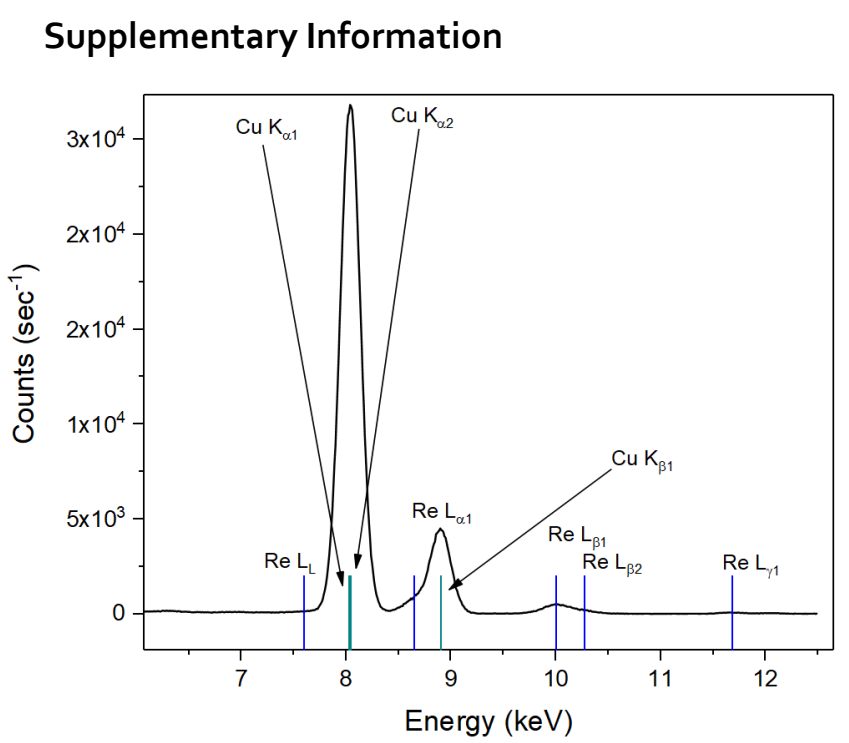

Figure S1: XRF spectrum of precursor residue after prolonged heating under deposition conditions. The strong $\mathrm{Cu}$ signals result from the copper tape used to hold the precursor residue.

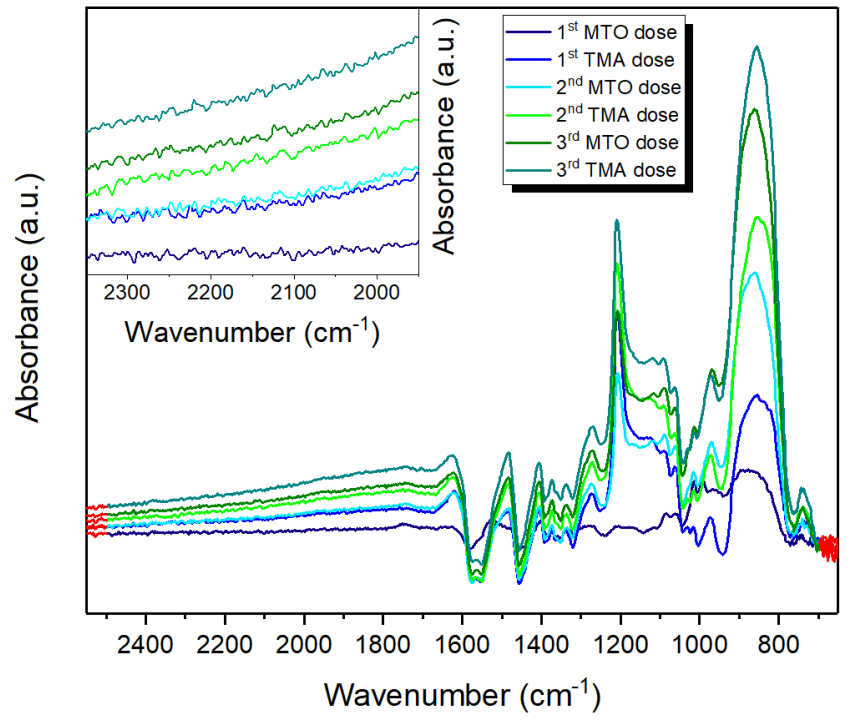

Figure S2: FTIR raw data of MTO and TMA half-cycles, recorded at $150{ }^{\circ} \mathrm{C}$ in vacuum. The inset shows the zoomed-in broad-band region. 


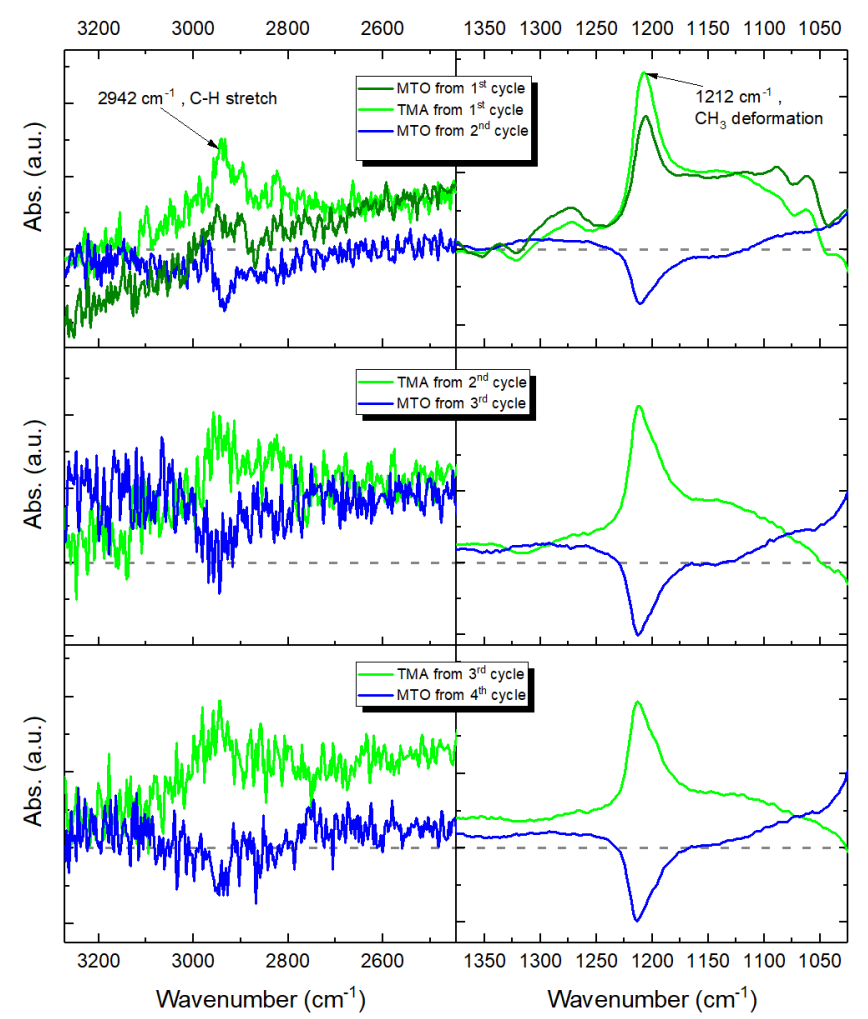

Figure $\mathrm{S}_{3}$ Enlarged areas of FTIR spectra for $\mathrm{sp}^{3} \mathrm{C}-\mathrm{H}$ modes around $2950 \mathrm{~cm}^{-1}$ and $1212 \mathrm{~cm}^{-1}$.

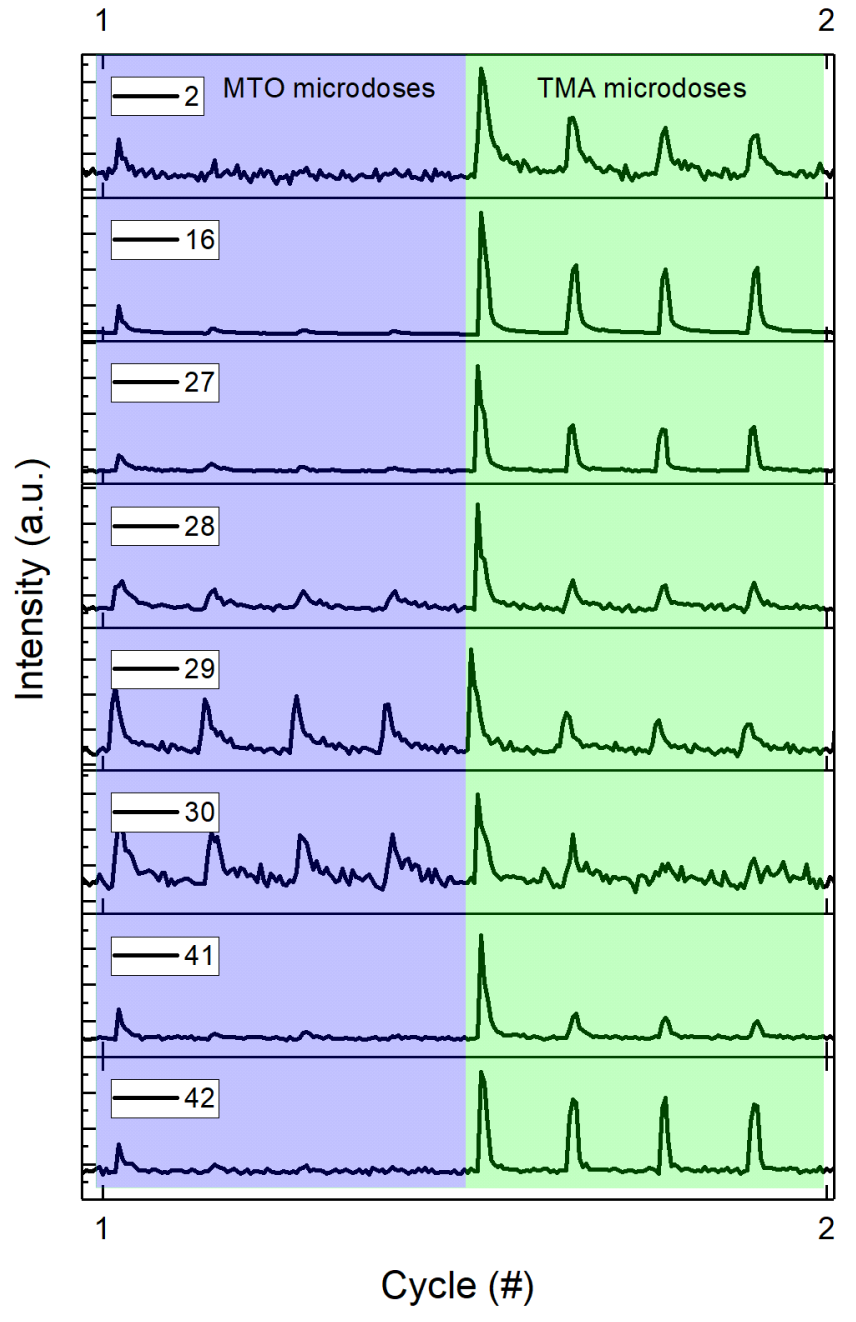

Figure S4: QMS trace of representative scans for different $m / z$ ratios. Scans were recorded during microdose experiments for both precursor, MTO and TMA, at $150^{\circ} \mathrm{C}$. 


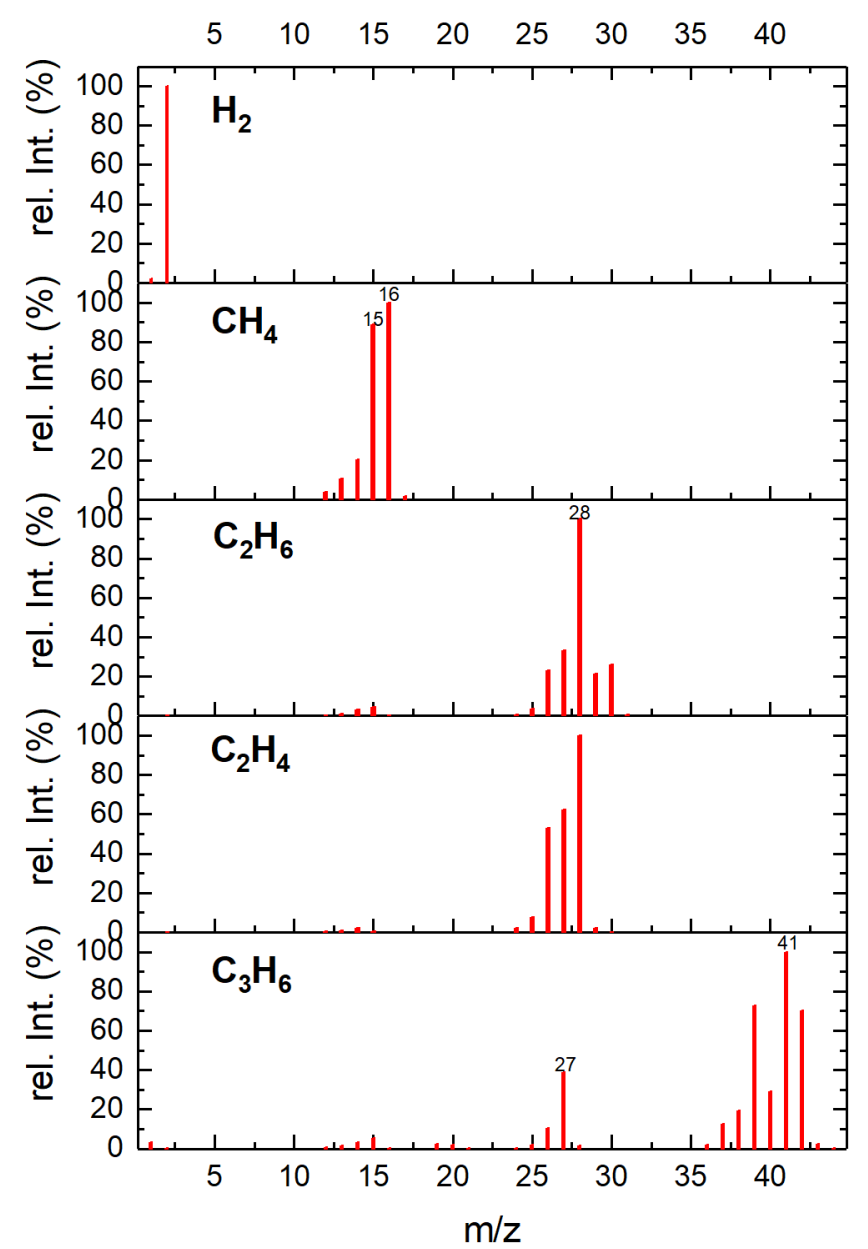

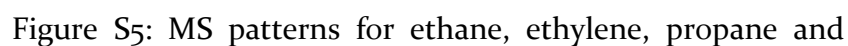
propylene, obtained from the NIST database ${ }^{1}$.

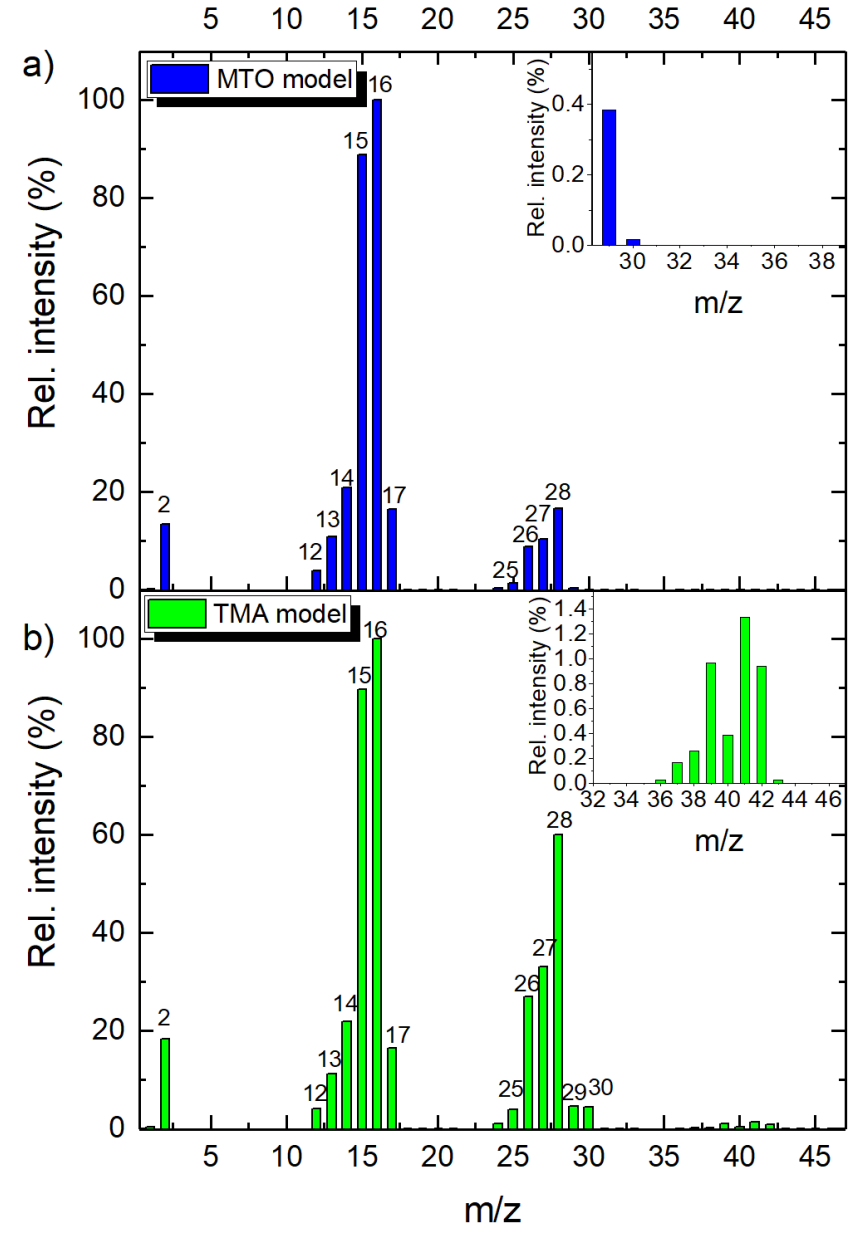

Figure S6: Modelled QMS trace for the two precursors MTO (a) and TMA (b), taking into account the potential products methane, ethane, ethylene, acetylene, propane, and propylene. The models were obtained from a linear combination of reference spectra.
1 Stein, S. E. NIST Chemistry WebBook, NIST Standard Reference Database Number 69; Mallard, W. G., Linstrom, P. J., Eds.; Gaithersburg MD, 20899. 


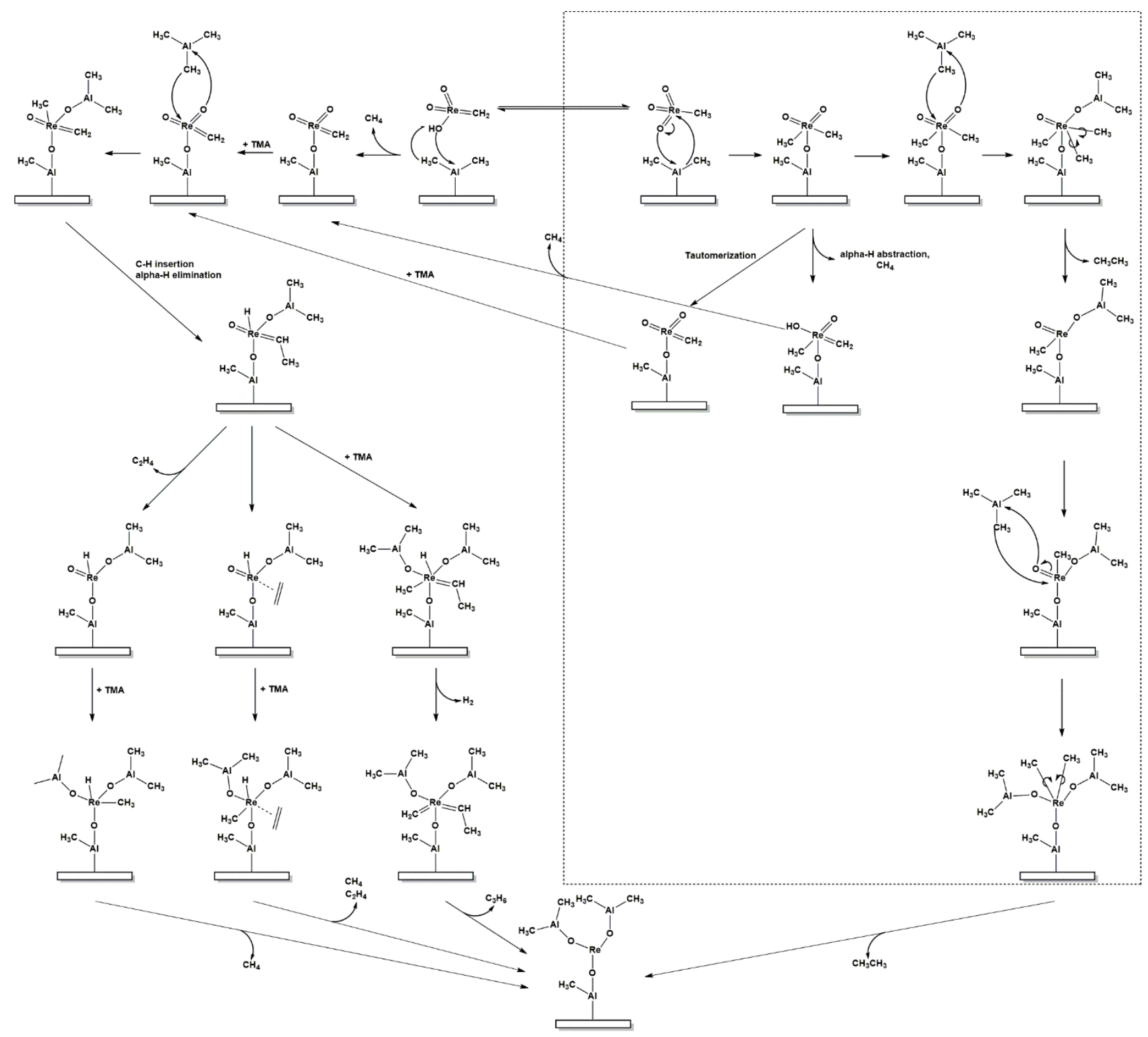

Scheme S1 : Additional mechanisms accounting for the formation of methane, ethylene, propylene and hydrogen during the TMA and MTO surface reactions. 


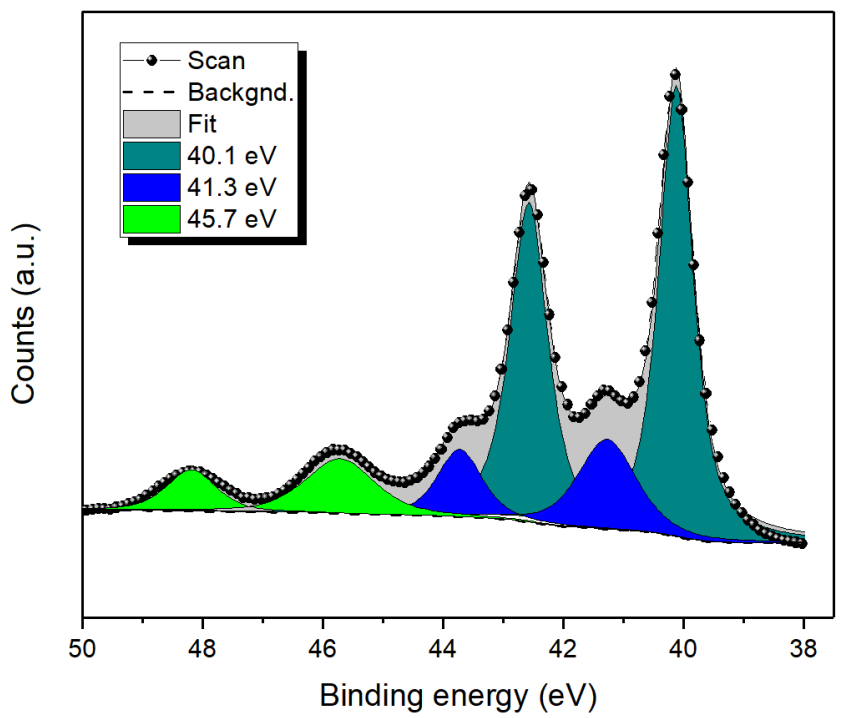

Figure $S_{7}$ : Re 4 XPS core level spectra, measured on a Re-foil. Re-foil was measured as-received without any treatment.

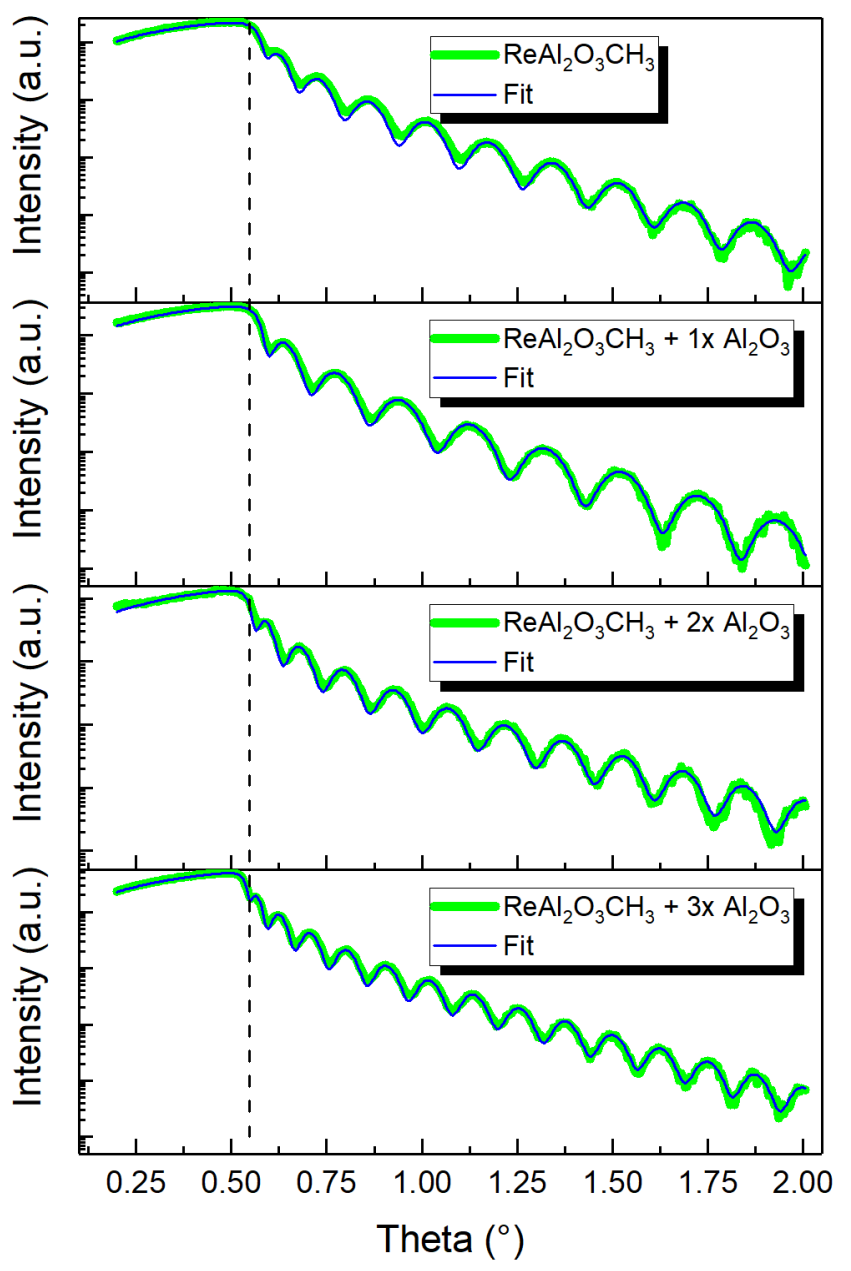

Figure S8: XRR measurements of bare $\mathrm{ReAl}_{2} \mathrm{O}_{3} \mathrm{CH}_{3}$ and $\mathrm{Al}_{2} \mathrm{O}_{3}$ blended $\mathrm{ReAl}_{2} \mathrm{O}_{3} \mathrm{CH}_{3}$ heterostructures. All thin films were grown at $150{ }^{\circ} \mathrm{C}$ using MTO and TMA. $\mathrm{Al}_{2} \mathrm{O}_{3}$ was deposited using TMA and water. In all cases, 100 ALD cycles were applied.

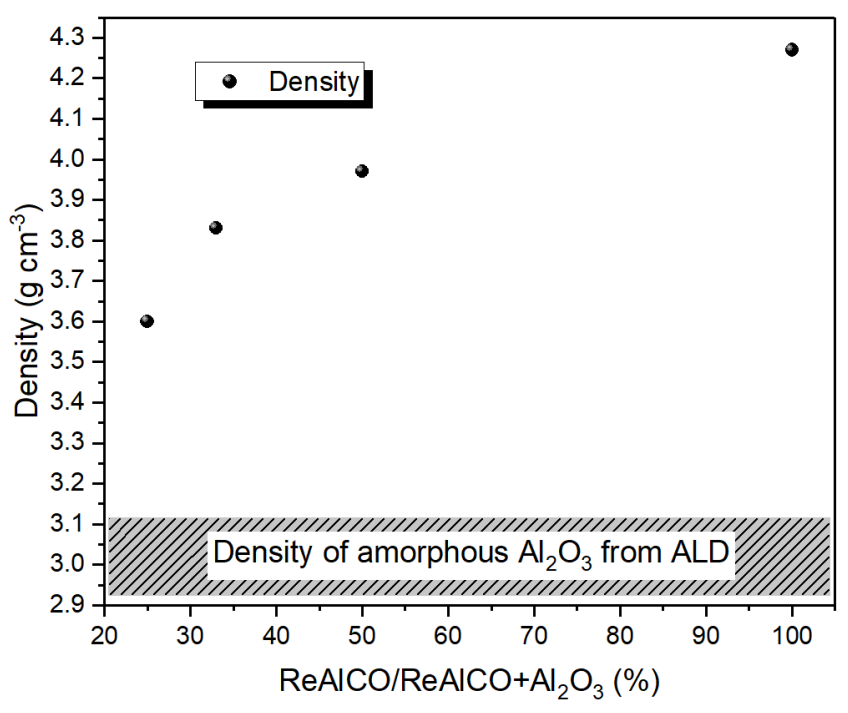

Figure S9: Densities of $\operatorname{ReAl}_{2} \mathrm{O}_{3} \mathrm{CH}_{3}$ and $\mathrm{ReAl}_{2} \mathrm{O}_{3} \mathrm{CH}_{3}$ blended with one, two or three layers of $\mathrm{Al}_{2} \mathrm{O}_{3}$. All samples were deposited at $150{ }^{\circ} \mathrm{C}$ using MTO and TMA. $\mathrm{Al}_{2} \mathrm{O}_{3}$ was deposited applying a standard sequence of TMA and $\mathrm{H}_{2} \mathrm{O}$ exposure.

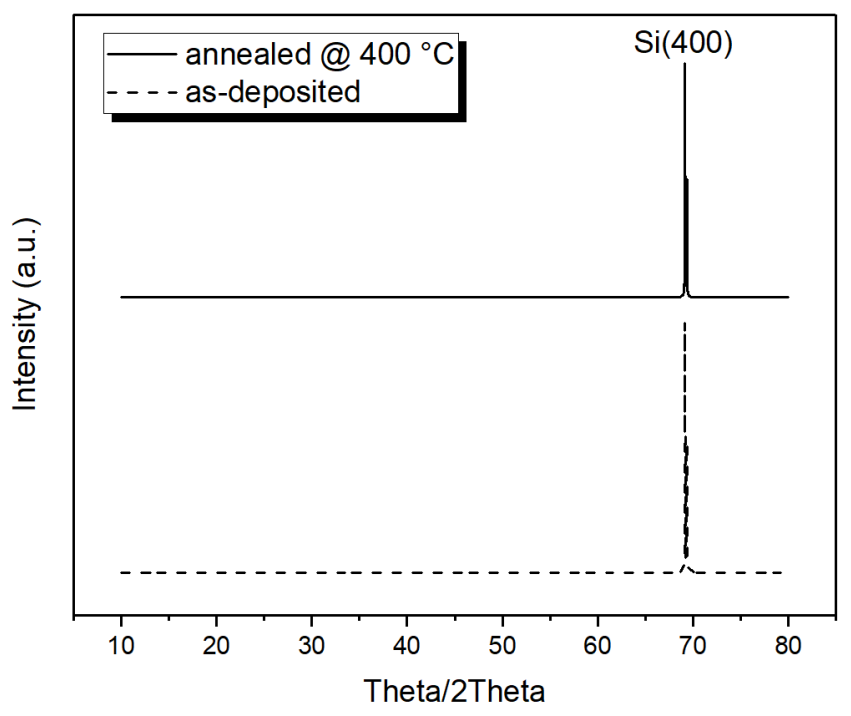

Figure S10: XRD pattern of a $35 \mathrm{~nm}$ thin film of $\operatorname{ReAl}_{2} \mathrm{O}_{3} \mathrm{CH}_{3}$ deposited at $150 \mathrm{C}^{\circ}$ on $\mathrm{Si}(100)$ using MTO and TMA. 


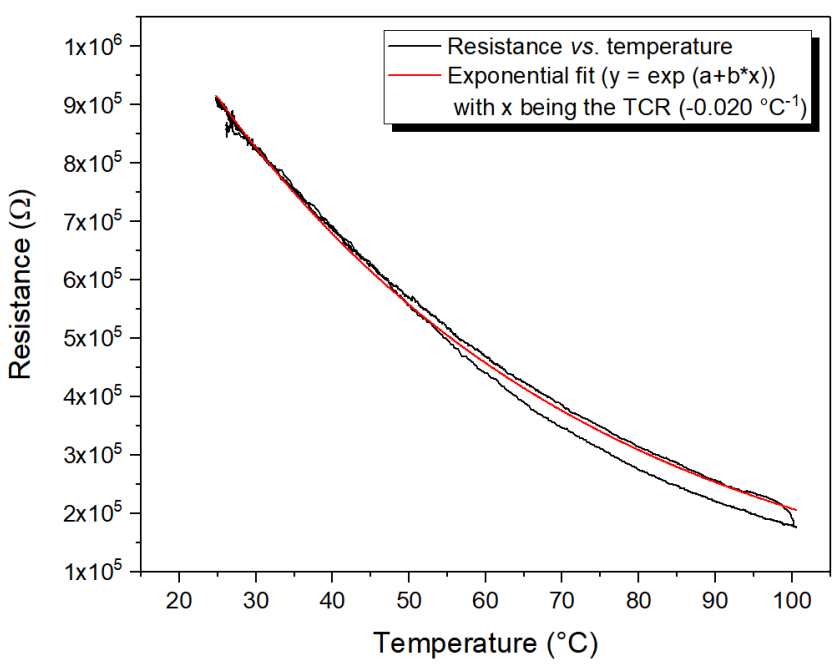

Figure S11: Plot of resistance vs. temperature from a representative $\mathrm{ReAl}_{2} \mathrm{O}_{3} \mathrm{CH}_{3}$ thin film (50 nm), deposited at 150 ${ }^{\circ} \mathrm{C}$, on an interdigitated electrode. The measurement was performed while applying a fixed potential of $1 \mathrm{~V}$ on a hot plate.

\section{Experimental Details}

\section{Hydrogen Forward Scattering (HFS):}

In an HFS experiment a detector is placed $30^{\circ}$ from the forward trajectory of the incident $\mathrm{He}^{++}$ion beam and the sample is rotated so that the incident beam strikes the surfaces $75^{\circ}$ from normal. A schematic diagram below shows the scattering geometry of a typical HFS experiment. In this geometry it is possible to collect light atoms, namely hydrogen, forward-scattered from a sample after collisions with the probing $\mathrm{He}^{++}$ion beam. A thin absorber foil is placed over the detector to filter out $\mathrm{He}^{++}$ions that are also forward scattered from the sample. Hydrogen concentrations are determined by comparing the number of hydrogen counts obtained from reference samples after normalizing by the stopping powers of the different materials. A hydrogen implanted silicon sample and a geological sample, muscovite, are used as references. The hydrogen concentration in the hydrogen implanted silicon sample is taken to be its stated implant dose of $1.6 \mathrm{E}_{17}$ $\pm 0.2 \mathrm{E} 17$ atoms $/ \mathrm{cm}^{2}$. The muscovite (MUSC) sample is known to have $\sim 6.5 \pm 0.5$ atomic percent hydrogen. Samples are checked for hydrogen loss in the analyzed region. This is done by acquiring spectra for different acquisition times (initially a short exposure followed by a longer exposure to the $\mathrm{He}^{++}$beam). Charge accumulations for 5 and $4 \mathrm{O} \mu \mathrm{C}$ are used. A lower proportional signal in the $40 \mu \mathrm{C}$ spectrum indicates hydrogen loss. In those cases the shorter exposure is chosen for analysis at the expense of higher noise in the spectrum. To account for surface hydrogen due to residual moisture or hydrocarbon adsorption a silicon control sample is analyzed together with the actual samples and the hydrogen signal from the control sample is subtracted from each of the spectra obtained from the actual samples. During the HFS acquisition backscattering spectra are acquired using the $160^{\circ}$ angle detector (with the sample in forward scattering orientation). The RBS spectra are used to normalize the total charge delivered to the sample.

\section{Fourier Transform Infrared Spectroscopy (FTIR):}

In situ FTIR studies of $\mathrm{ReAl}_{2} \mathrm{O}_{3} \mathrm{CH}_{3}$ ALD were conducted in transmission mode with a Nicolet 6700 FTIR spectrometer (Thermo Scientific) using a separate, smaller ALD reactor designed specifically for FTIR measurements that is similar to previously-described systems. ${ }^{1,2}$ The FTIR reactor used gate valves that were closed during the precursor exposures to avoid growth on the IR-transparent CsI windows. The FTIR substrates were prepared by pressing $\mathrm{ZrO}_{2}$ nanopowder ( $<100 \mathrm{~nm}$ diameter) into a stainless steel grid. ${ }^{3} \mathrm{The}_{\mathrm{ZrO}_{2}}$ nanopowder is relatively transparent in the range of interest $\left(4000-800 \mathrm{~cm}^{-1}\right)$ and the high surface area of the pressed powder boots the IR absorption by $2-3$ orders of magnitude compared to a single monolayer. The commercial grids were manufactured via photochemical machining (Fotofab, Inc.) and had a thickness of 50 microns with 50 micron bars and 200 micron square openings. The FTIR substrate grid was mounted into a resistively-heated sample stage with a maximum operating temperature of $500{ }^{\circ} \mathrm{C}$. When the sample stage was installed in the FTIR reactor, the IR beam passed through the center of the FTIR substrate grid. During in situ FTIR measurements, the substrate temperature was maintained at $150{ }^{\circ} \mathrm{C}$ by the heated stage and the reactor walls were heated separately to $150{ }^{\circ} \mathrm{C}$ to avoid condensation of the ALD precursors.

\section{References:}

1) Ferguson, J. D.; Weimer, A. W.; George, S. M. Thin Solid Films 2000, 371, 95-104.

2) Goldstein, D. N.; McCormick, J. A.; George, S. M. J. Phys. Chem. C 2008, 112, 19530-19539.

3) Ballinger, T. H.; Wong, J. C. S.; Yates, J. T. Langmuir 1992, $8,1676-1678$. 